\section{FABRICATION PROCESS AND}

\author{
BASIC MATERIAL \\ PROPERTIES OF THE BASF \\ ULTRAFUSE 316LX \\ MATERIAL
}

\begin{abstract}
JIRI SAFKA ${ }^{1}$, MICHAL ACKERMANN ${ }^{2}$, JAKUB MACHACEK ${ }^{1}$, MARTIN SEIDL ${ }^{2}$, FILIP VELE ${ }^{1}$, VERONIKA TRUXOVA ${ }^{2}$
\end{abstract}

Technical University of Liberec, ${ }^{1}$ Faculty of Mechanical Engineering, ${ }^{2}$ Institute for Nanomaterials, Advanced Technologies and Innovation, Liberec, Czech Republic DOI: 10.17973/MMSJ.2020_12_2020071

Jiri.safka@tul.cz

The presented article deals with the research of commercially available BASF Ultrafuse $316 \mathrm{LX}$ filament intended for processing by the Fused Filament Fabrication additive technology. This material contains a high proportion of metal particles. The aim of the research was to compare the resulting mechanical properties of the Ultrafuse 316LX not only with conventional rolled AISI 316L stainless steel, but also with the AISI 316L material processed by another additive technology Selective Laser Melting. Several sets of tensile test specimens were printed from Ultrafuse $316 \mathrm{LX}$ using Felix Tec4 machine to determine specific mechanical properties. The same sets of samples were made from AISI 316L powder using Selective Laser Melting additive technology for direct comparison of selected mechanical properties. After the whole manufacturing process, the Ultrafuse $316 \mathrm{LX}$ show very interesting mechanical properties with adequate strength and increased ductility.

\section{KEYWORDS}

Additive manufacturing, Fused Filament Fabrication, FFF, Metal printing, Mechanical properties, SEM, sintering.

\section{INTRODUCTION}

$3 \mathrm{D}$ printing is a progressive fabrication method that allows the production of parts with very complex shape. This is ensured by layer-by-layer adding of the material [Chua 2014]. Using this approach, it is possible to lighten inner core of the part and thus save the input material [Wohlers 2014]. Nowadays, the 3D additive technologies enable to process various materials such as metals, ceramics and photopolymers. [Gibson 2014].

Currently, metal 3D printing is most often realised with the use of so-called powder bed technologies. Main defining representatives are Selective Laser Melting (SLM), Direct Metal Laser Sintering (DMLS) and Electron Beam Melting (EBM) [Buchanan 2019]. In the frame of the printing process, the material is melted in the inert atmosphere or vacuum. However, there are other technologies on the market, such as BinderJet, which uses special binders (adhesives) to join the individual grains of the processed metal material. However, the resulting model must undergo other processing steps that ensure its resulting mechanical properties. The main disadvantage of the technologies described above is their high acquisition and running costs. For this reason, BASF decided to use its knowledge of Metal Injection Moulding (MIM) technology and transfer it into the field of 3D printing, specifically FFF technology. The result of their research activities is the Ultrafuse $316 \mathrm{LX}$ material, which contains more than 80 percent of $316 \mathrm{~L}$ metal powder [Forward AM 2020]. This metal powder is supplemented with a polymeric carrier, which allows the material to be extruded into the form of a filament, which can be further processed by FFF technology. At the current level of knowledge, only few articles deal with production of Ultrafuse $316 \mathrm{LX}$ material on standard FFF machines [Thompson 2019]. Therefore, this article tends to fill this gap by mapping the fabrication process on the commercially available Felix Tec4 printer and by evaluation of basic mechanical properties of the material.

FFF technology is widely used for 3D printing of polymeric materials - plastics [Fernandez 2015]. Currently, there are a large number of manufacturers of machines for 3D printing of plastics. On the other hand, development of equipment dedicated to FFF 3D printing of metals is not solved in such a wide range. There are now two major players in the commercial sector which process metal powder in the form of the filament. Markforged, Inc. is the first one with Atomic Diffusion Additive Manufacturing (ADAM) technology and Metal X equipment [Markforged 2020]. Desktop Metal, Inc. is the second, equally important player with the Studio System printing solution [Desktopmetal 2020]. The first mentioned Markforged uses metal in a polymer carrier in the form of a long string (filament) wound on a spool. The Desktop Metal uses metal in a special wax polymer, which is provided in the form of short, narrow rods. Both companies use two types of materials during their printing process. The first material forms the product body and also the support structures. Second material consists of a ceramic powder and a carrier and it is intended as a separation site between support structures and the part. With this approach, the part and support structure are prevented to merge together during further chemical and thermal processes.

\section{BASF ULTRAFUSE 316LX FILAMENT}

Ultrafuse 316LX material is a product of BASF 3D Printing Solutions $\mathrm{GmbH}$. It is a material intended for processing on any 3D printer designed for FDM or FFF technology. The material consists of a polymeric carrier (binder) and AISI 316L (DIN 1.4404) stainless steel metal powder. Figure 1 shows a crosssection of the filament under scanning electron microscope (SEM).

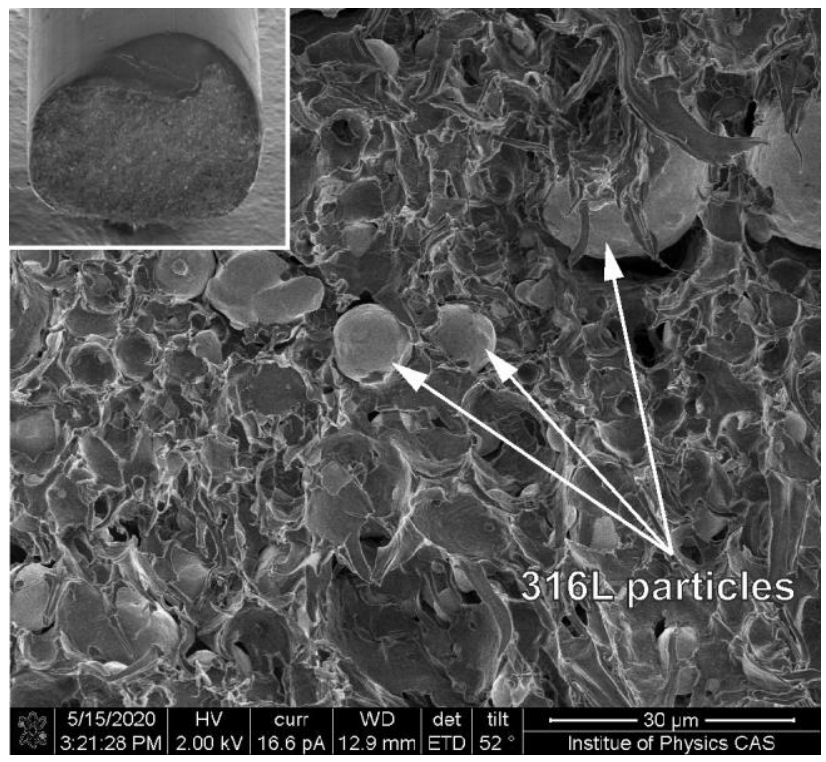

Figure 1: SEM images of BASF Ultrafuse 316LX filament cross-section

BASF indicates metal powder content within the filament of more than $80 \mathrm{wt} \%$. BASF developed Ultrafuse 316LX based on 
its experience with Metal Injection Moulding (MIM) technology [Gong 2018]. The material is thus based on materials dedicated for MIM technology, where BASF has been operating as a supplier of materials for many years. The procedure for working with the Ultrafuse $316 \mathrm{LX}$ material is thus identical with the procedure for processing metal products using MIM technology. The $316 \mathrm{~L}$ particles in the filament were examined using Energy-dispersive X-ray spectroscopy (EDS) for evaluation of its chemical composition. Results are summarized in Table 1. The composition is in agreement with standard specifications of AISI 316L stainless steel [AZOM 2020].

\begin{tabular}{|c|}
\hline Element \\
\hline $\mathrm{Si}$ \\
\hline $\mathrm{Mo}$ \\
\hline $\mathrm{Cr}$ \\
\hline $\mathrm{Fe}$ \\
\hline $\mathrm{Ni}$
\end{tabular}

\begin{tabular}{|c|c|}
\hline Wt. \% & At. \% \\
\hline 0.9 & 1.63 \\
\hline 2.98 & 1.59 \\
\hline 17.07 & 16.9 \\
\hline 66.3 & 60.78 \\
\hline 9.29 & 8.1 \\
\hline
\end{tabular}

Table 1. Chemical elements of at the filament ULTRAFUSE 316 LX sample.

In the first step, the so-called Green Part is made. It is a part containing a polymeric carrier with a metal. The Green Part must then go through the debinding process, where most of the binder is removed and the model enters its next phase, the so-called Brown part. The brown part already composes almost exclusively of metal powder with only a minimal amount of binder on the edges of the metal powder grains and it does not yet achieve the required mechanical properties. The brown part is therefore very prone to damage of the geometry during manipulation.

In the last step, the part is sintered, thus removing the residual binder and joining the metal particles together. After this operation, the final metal part without any internal stress is ready. During sintering, the parts shrink. Excessive shrinkage can also lead to deformations of the geometry, if the part or its support is improperly designed. The entire process of Ultrafuse 316LX filament preparation together with its processing by FFF technology and post-processing operations including debinding and sintering of the part is shown in Figure 2.

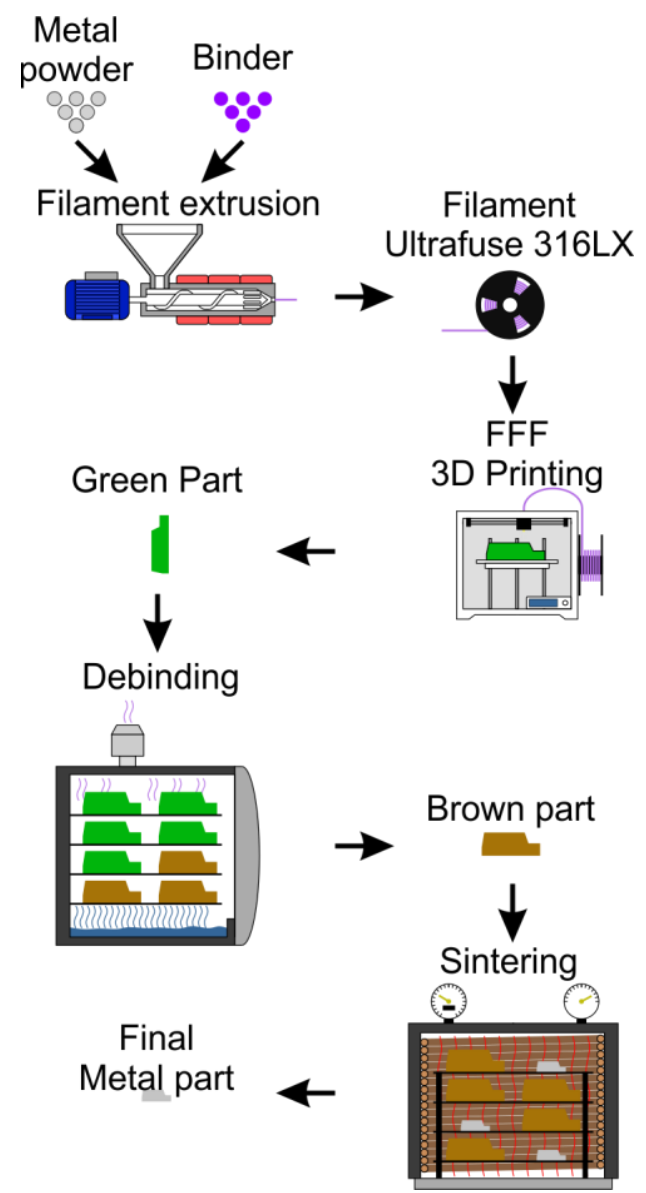

Figure 2. Technological process for producing the final part from BASF 316LX filament

\section{MATERIALS AND METHODS}

Mechanical testing and subsequent analysis of gathered data offer the possibility to compare different groups of tested materials. For the purpose of this paper, tensile test was chosen for qualitative assessment of the basic mechanical constants.

\subsection{Fabrication of specimens}

Here performed tensile tests were not done in accordance with usual standards for metallic materials such as ISO 6892 and ASTM E8. This is due to the fact that these standards recommend specimens with circular cross-area, typically with the diameter of $6 \mathrm{~mm}$. With respect to current technological limitations of FFF technology for processing of metallic filaments, different form of the specimens had to be chosen. Standard specimens would be not only hard to produce with appropriate precision but the main problem lies in the two finalizing steps - debinding and sintering. During these steps, parts with walls thicker than $4 \mathrm{~mm}$ are susceptible to occurrence of cracks and large deformations. Moreover, support structures must be manufactured from the source material. In our case, no separation material is available as it was descried for Markforged and Desktop Metal solutions. In the end, the 1BA shape from ISO 527 (Plastics - Determination of tensile properties) was employed (Figure 3 ). 


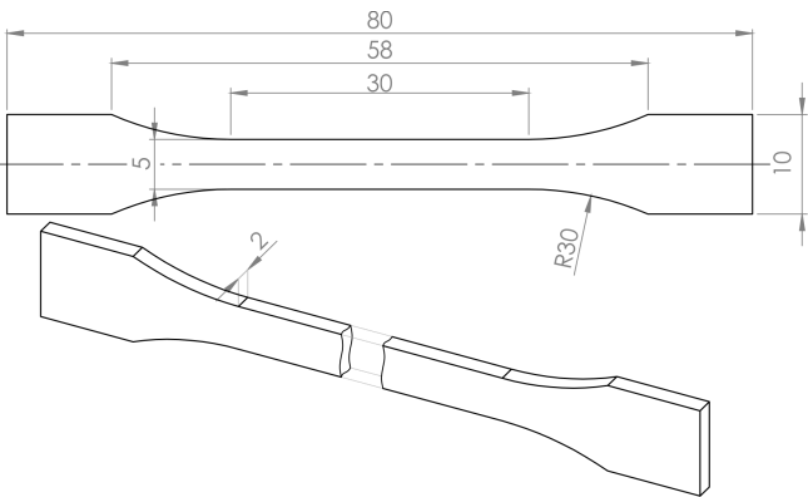

Figure 3. Dimensions of tensile test specimen

In the case of tensile testing, seven groups of samples were created. Overview of individual groups together with brief description is indicated in Table 2.

\begin{tabular}{c|l|c|}
\hline $\begin{array}{c}\text { Group } \\
\text { designation }\end{array}$ & \multicolumn{1}{|c|}{ Description } & $\begin{array}{c}\text { Number } \\
\text { of } \\
\text { samples }\end{array}$ \\
\hline Laser & $\begin{array}{l}\text { 316L rolled material } \\
\text { Laser cut from sheet plate }\end{array}$ & 5 \\
\hline Water & $\begin{array}{l}\text { 316L rolled material } \\
\text { Water cut from sheet plate }\end{array}$ & 5 \\
\hline SLM_AB & $\begin{array}{l}\text { SLM-printed 316L specimens } \\
\text { As-built condition }\end{array}$ & 5 \\
\hline SLM_M & $\begin{array}{l}\text { SLM-printed 316L specimens } \\
\text { Finished by milling }\end{array}$ & 5 \\
\hline UTF_BASF & $\begin{array}{l}\text { Ultrafuse 316LX } \\
\text { Fabrication of specimens: TUL } \\
\text { Debinding and sintering: BASF }\end{array}$ & 5 \\
\hline UTF_TUL & $\begin{array}{l}\text { Ultrafuse 316LX } \\
\text { Fabrication of specimens: TUL } \\
\text { Debinding and sintering: TUL }\end{array}$ & 5 \\
\hline UTF_Vibrom & $\begin{array}{l}\text { Ultrafuse 316LX } \\
\text { Fabrication of specimens: TUL } \\
\text { Debinding and sintering: Vibrom }\end{array}$ & 5 \\
\hline
\end{tabular}

Table 2. Overview of tested groups

First two groups marked Laser and Water refer to samples from $2 \mathrm{~mm}$ thick $316 \mathrm{~L}$ stainless steel sheet plate. The shape given in Figure 3 was cut from this sheet by laser beam and water jet, respectively. Thanks to these two groups, it is possible to compare mechanical properties of BASF Ultrafuse $316 \mathrm{LX}$ products with standard rolled material. Use of water jet can also eliminate influence of heat on the value of standard mechanical constants which may be present for laser cutting.

Following two groups marked $S L M \_A B$ and $S L M \_M$ denote specimens fabricated using Selective Laser Melting technology and 316L stainless steel powder (supplier SLM Solutions Group AG, Lübeck, Germany). For both of these groups, the specimens were built in horizontal position using SLM280HL machine. For $S L M \_A B$ group, the only operation after finishing of the job was removal of support structures and thus this state represent the as-built condition. In the case of SLM_M group, given samples were finished using milling operations. Table 3 summarizes SLM process parameters which were used for fabrication of specimens from $316 \mathrm{~L}$ stainless steel powder.

\begin{tabular}{|c|l|}
\hline Parameter & Value \\
\hline Laser power & $175 \mathrm{~W}$ \\
\hline Scanning speed & $750 \mathrm{~mm} / \mathrm{s}$ \\
\hline Layer thickness & $0.03 \mathrm{~mm}$ \\
\hline Hatch distance & $0.12 \mathrm{~mm}$ \\
\hline
\end{tabular}

Table 3. SLM process parameters for AISI 316L steel.

Last three groups refer to main topic of this article - the Ultrafuse 316LX filament. All the samples were fabricated at Technical University of Liberec using Felix Tec4 machine (FELIXprinters, IJsselstein, The Netherlands) with technological parameters listed in Table 4. Specimens were fabricated in horizontal orientation.

\begin{tabular}{|c|l|}
\hline Parameter & Value \\
\hline Nozzle size & $0.5 \mathrm{~mm}$ \\
\hline Extrusion multiplier & 1.06 \\
\hline Extrusion width & $0.4 \mathrm{~mm}$ \\
\hline Retraction distance & $1 \mathrm{~mm}$ \\
\hline Retraction speed & $45 \mathrm{~mm} / \mathrm{s}$ \\
\hline Layer height & $0.15 \mathrm{~mm}$ \\
\hline Outlines & 2 \\
\hline Infill & $100 \%$ \\
\hline Outline overlap & $30 \%$ \\
\hline Nozzle temperature & $245{ }^{\circ} \mathrm{C}$ \\
\hline Bed temperature & $80^{\circ} \mathrm{C}$ \\
\hline Default print speed & $30 \mathrm{~mm} / \mathrm{s}$ \\
\hline
\end{tabular}

Table 4. Technological parameters used for production of specimens from Ultrafuse $316 \mathrm{LX}$ filament.

In Figure 4, a snapshot from fabrication process of cubic sample from Ultrafuse $316 \mathrm{LX}$ material is shown. During the filament extrusion, liquefied material creates very dense compound which frequently sticks to the lower surface of extrusion nozzle. The material itself is very abrasive and thus it demands utilisation of a special hard nozzle or its replacement after a few extrusion cycles.

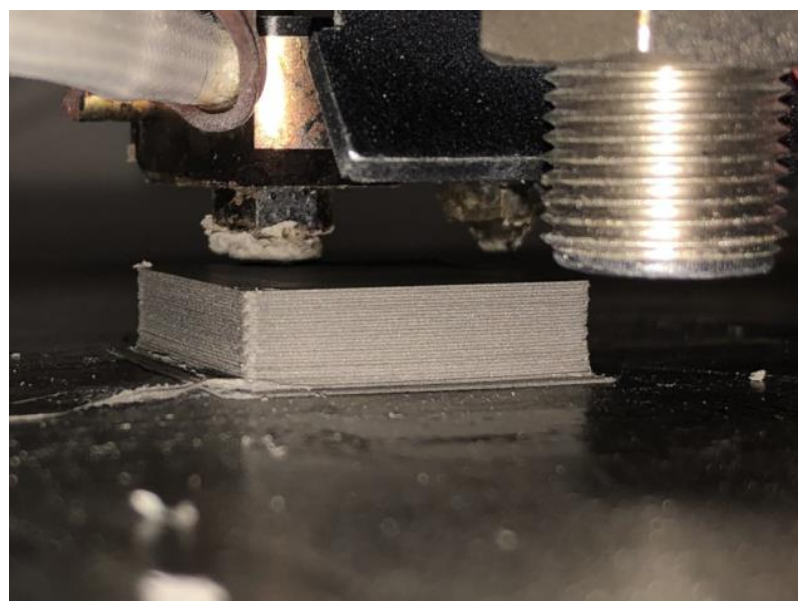

Figure 4. Extrusion of Ultrafuse 316LX filament on Felix Tec4 machine. 
For the following steps, debinding and sintering, three different suppliers were tested. Firstly, manufacturer of the filament BASF offered to arrange finishing operations. This group is marked UTF_BASF. In the second case, finishing operations were done at the premises of Technical University of Liberec, hence the abbreviation UTF_TUL. Catalytic debinding was done in custom-made chamber using small doses of nitric acid. Overview of the whole device can be seen in Figure 5 . The chamber itself is composed of 3.7 I glass jar and the inner plate made of $304 \mathrm{~L}$ stainless steel which holds the products during the whole process. For better evaporation of the acid, the jar was heated to temperature of $80^{\circ} \mathrm{C}$. Side product of the debinding process - the inner gas was continuously removed from the jar into an exhaust system.

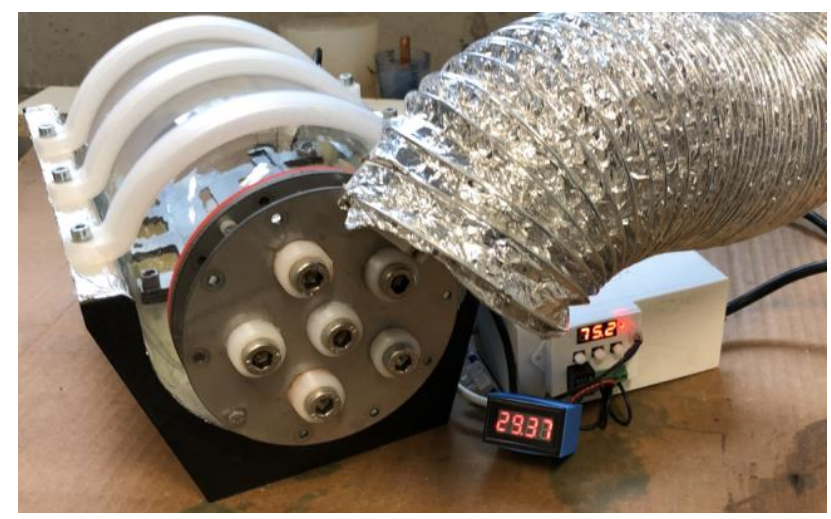

Figure 5. Custom-made chamber for debinding.

Consequently, products were submitted to sintering in vaccum furnace using $1380^{\circ} \mathrm{C}$ process temperature. Last group named UTF_Vibrom refers to finishing in the company Vibrom s.r.o. (Třebechovice pod Orebem, Czech Republic) which is a Czech leader in Metal Injection Moulding (MIM) technology. This technology uses similar post-processes described in this article. Moreover, the company frequently operate with source products from BASF. Thus, a possibility to use Vibrom's knowledge and equipment were tested for finishing of Ultrafuse $316 \mathrm{LX}$ products. In Figure 6, all the additively manufactured specimens are displayed.

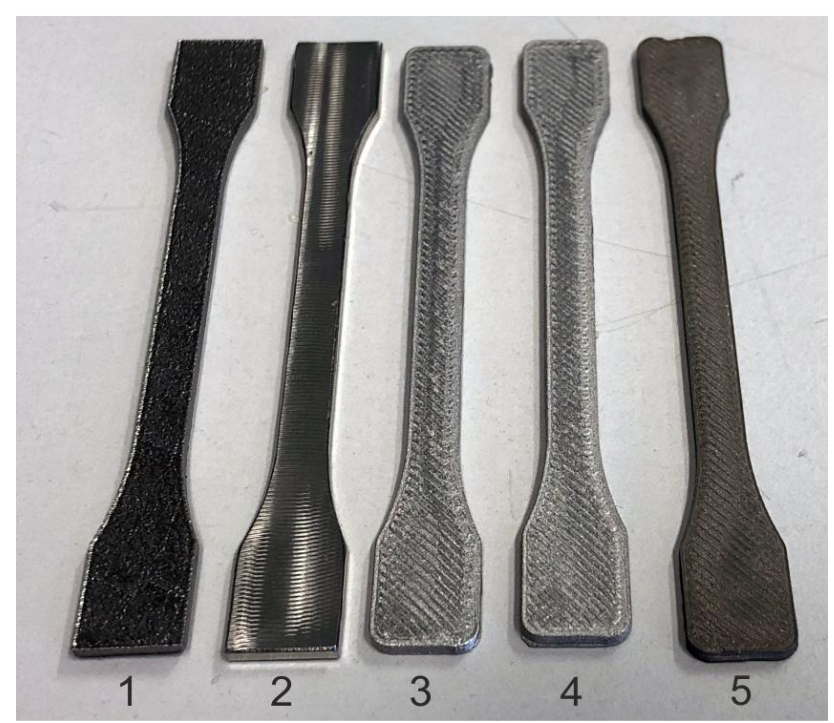

Figure 6. Additively manufactured tensile test specimens. 1-SLM_AB, 2-SLM_M,3-UTF_BASF, 4-UTF_Vibrom, 5-UTF_TUL

\subsection{Conditions of tensile tests}

All the specimens underwent tensile test for determining the basic mechanical properties of tested materials. Initial tests failed due to slippage of the specimen from standard pneumatic clamping system. This was caused because of small clamping area of the specimen in combination with low value of clamping force. To solve this problem, special clamps were designed and manufactured from DIN 1.2709 tool steel using Selective Laser Melting technology. Using this process, it was possible to fit inner part of the clamp directly to the R30 radius (see Figure 3 ) between clamping and testing part of the specimen.

Tensile tests were carried out on TiraTest universal testing frame, equipped with $\pm 100 \mathrm{kN}$ force transducer HBM (Hottinger Brüel \& Kjaer $\mathrm{GmbH}$, Germany). Each test was position-driven with defined speed rate of the machine's crosshead. Strain was measured with the use of MFL 800-B (MF Mess- \& Feinwerktechnik GmbH, Germany) extensometer with initial distance $L_{0}=15 \mathrm{~mm}$ between the blades. Before the test itself, preload of $300 \mathrm{~N}$ was applied to ensure proper position of the specimen in the clamps without any clearance. After this step, blades of the extensometer were attached to the specimen (Figure 7). In the initial part, constant speed rate of $1 \mathrm{~mm} / \mathrm{min}$ was applied. After reaching $2 \%$ strain, the speed was gradually increased up to $15 \mathrm{~mm} / \mathrm{min}$ and this value remained constant until rupture of the specimen.

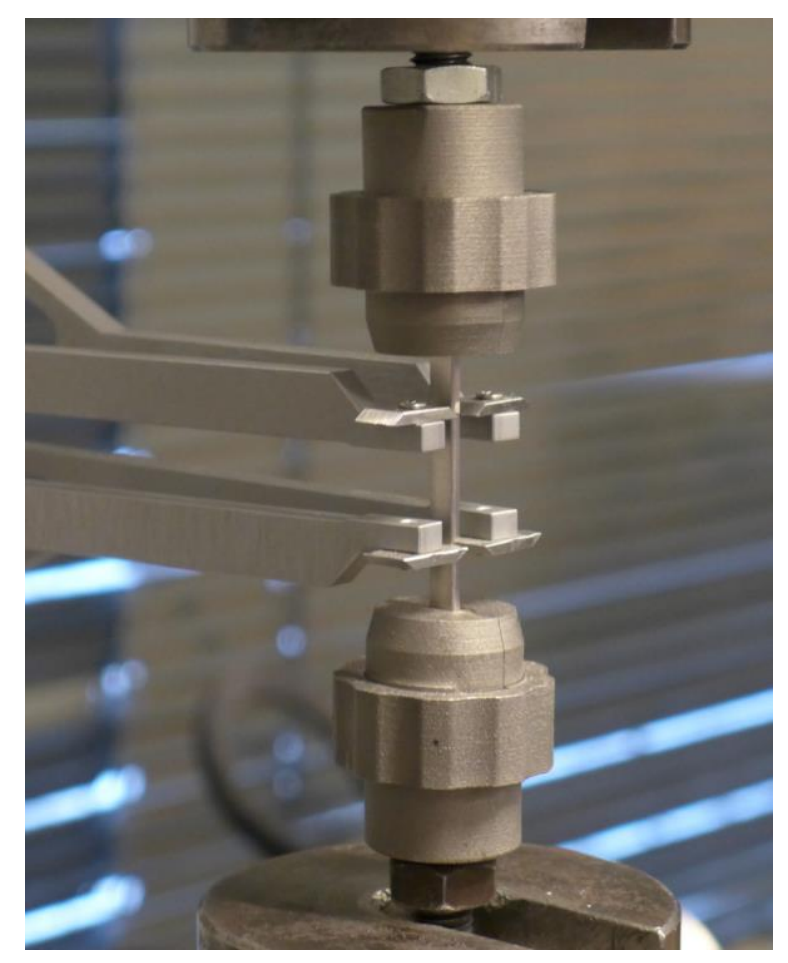

Figure 7. Tensile specimen in custom made clamps

\section{RESULTS}

For the first two groups of specimens which were extracted from 316L sheet plate (supplier Pronton s.r.o., Liberec, Czech Republic), the behaviour during the test is almost identical. Tensile curves for all the five tests from the Laser group are shown in Figure 8. As apparent, the curves almost overlap each other. The samples show no change not only for standard stress levels such as Ultimate tensile strength but also the value of strain at break. This behaviour was observed for both laser and water cut specimens. 


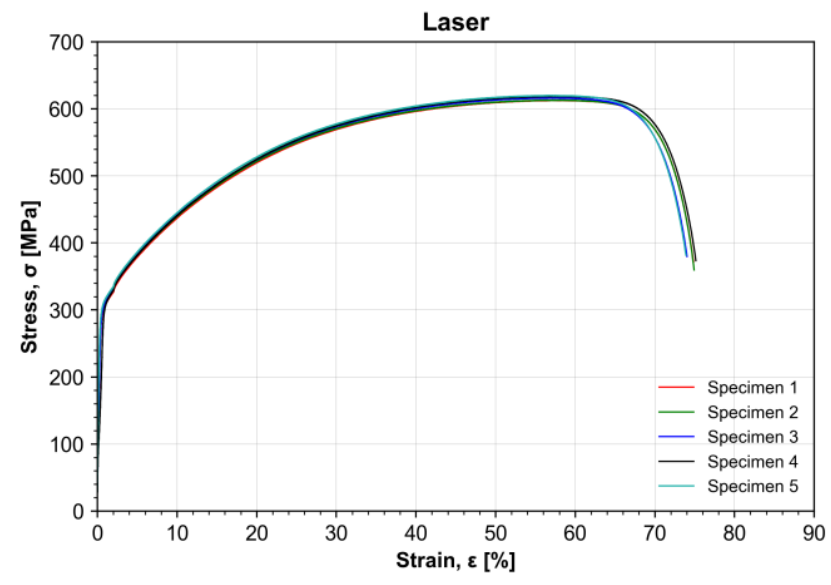

Figure 8. Tensile curves for samples from 316L sheet plate, cut by laser.

In the case of SLM-printed specimens, more scatter in the data can be seen. This is especially visible for strain at break value. As an example, stress-strain curves in Figure 9 are plotted for the specimens in as-built condition. In comparison with previous group, the ultimate tensile stress value is lowered. This may be caused by coarse surface of the unfinished specimens.

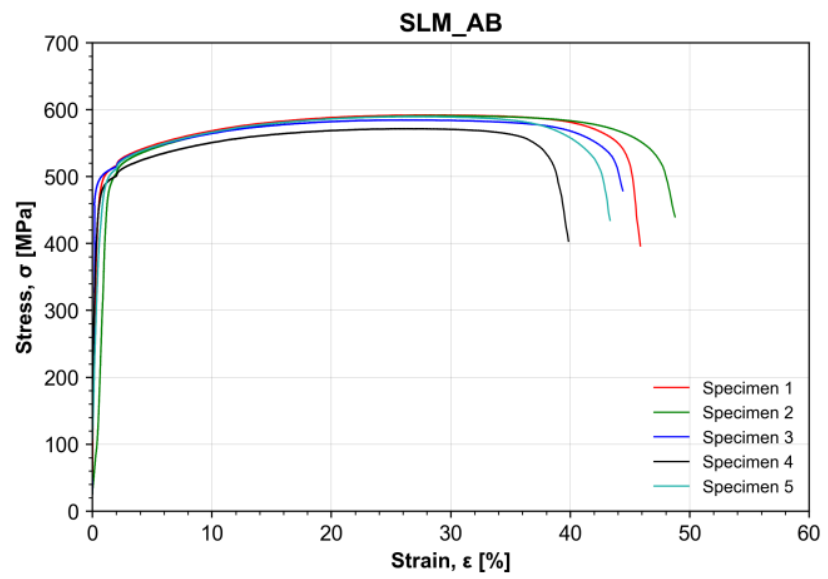

Figure 9. Tensile curves for samples fabricated with the use of SLM technology in an as-built condition.

BASF Ultrafuse 316LX specimens, which were post-processed in manufacturer's facility, show large strains before the rupture occurs. The value of strain at break reaches almost $90 \%$. Repeatability of the test is also outstanding as the only major difference can be seen at the end of stress-strain curves (Figure 10).

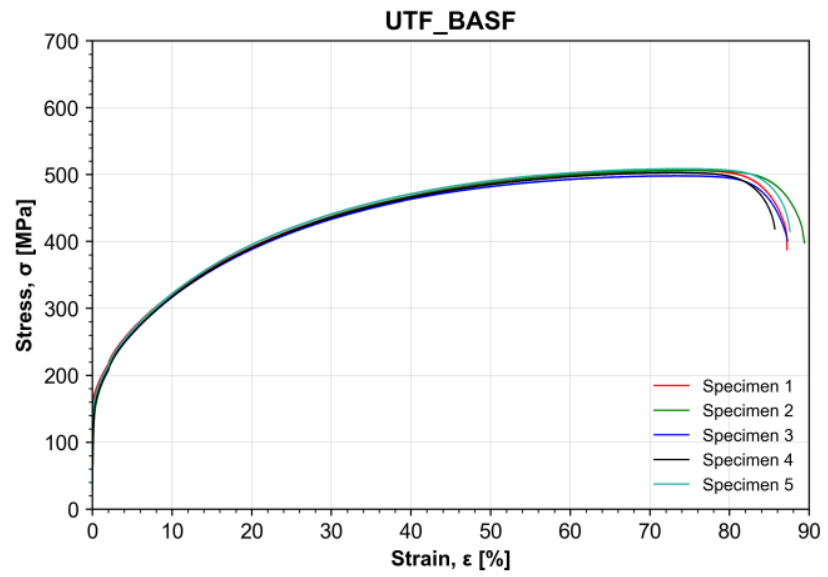

Figure 10. Tensile curves for Ultrafuse specimens, post-processed in the BASF company.
Due to the space limitations of this paper and better comparison of tested groups of specimens, standard mechanical constants were derived from related stress-strain curves. In Figure 11, Offset Yield stress $R_{p 0,2}[\mathrm{MPa}$ ] and Ultimate Tensile Stress $R_{m}[\mathrm{MPa}$ ] are displayed in the form of bar graph.

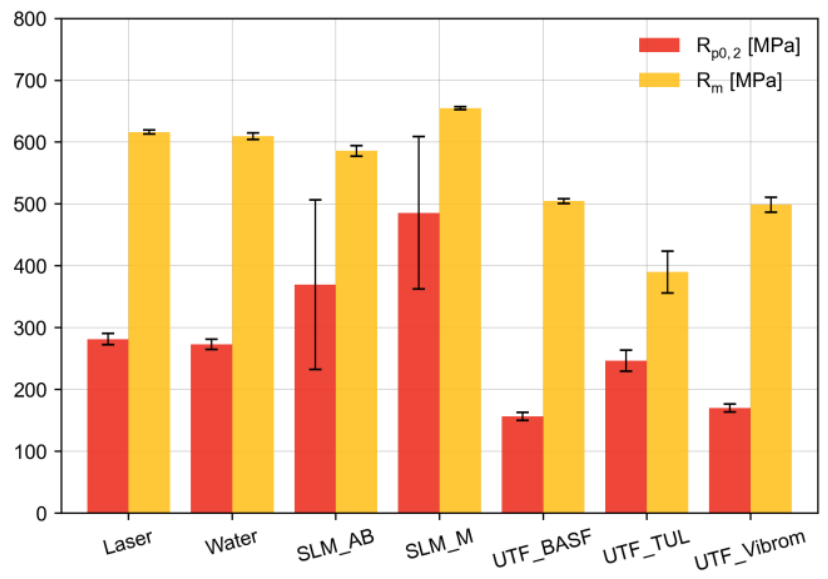

Figure 11. Ultimate Tensile Stress $R_{m}$ and Offset Yield Stress $R_{p 0,2}$ Mean value and standard deviation from five measurements.

Figure 12 show the same type of graph for strain at break $\varepsilon_{b}$ [\%] quantity.

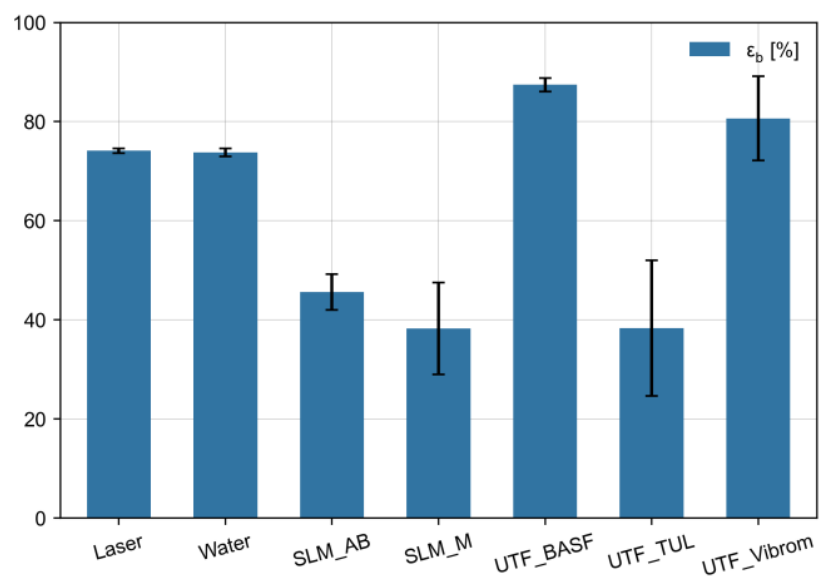

Figure 12. Strain at break $\varepsilon_{\mathrm{b}}$. Mean value and standard deviation from five measurements.

\section{DISCUSSION}

In Ultrafuse 316LX material list from BASF Company, it is possible to find basic mechanical properties of the material [Forward AM 2020]. Similarly, SLM Solution Group AG presents standard material constants for $316 \mathrm{~L}$ stainless steel in their material sheet [SLM 2020]. According to these materials, the tensile tests were done in agreement with DIN EN ISO 6892 for Ultrafuse material. SLM Solutions Group does not state any standard under which the tests were done. Mechanical properties found in above mentioned materials are summarized in Table 5.

\begin{tabular}{|c|c|c|c|}
\hline Material & $\begin{array}{c}\text { Tensile strength } \\
\mathrm{R}_{\mathrm{m}}[\mathrm{MPa}]\end{array}$ & $\begin{array}{c}\text { Yield strength } \\
\mathrm{R}_{\mathrm{p} 0.2}[\mathrm{MPa}]\end{array}$ & $\begin{array}{c}\text { Ductility } \\
\mathrm{A}[\%]\end{array}$ \\
\hline $\begin{array}{c}\text { Ultrafuse } \\
316 \mathrm{LX}\end{array}$ & 561 & 251 & 53 \\
\hline SLM 316L & 620 & 505 & 43 \\
\hline
\end{tabular}

Table 5. Material constants for tested materials derived from manufacturer datasheet. 
When comparing results of mechanical tests, several outcomes can be stated. First of all, specimens from rolled $316 \mathrm{~L}$ stee show almost identical behaviour regardless of the method by which they were cut from source sheet plate. Results are consistent in both strength and ductility values.

Ultrafuse $316 \mathrm{LX}$ does not reach the strength of here tested rolled material. Standard stress values are more than $100 \mathrm{MPa}$ lower than for the specimens from sheet plate. The values of Yield stress and Ultimate tensile stress does not correspond with data from the manufacturer. Again, the values are about $60 \mathrm{MPa}$ lower for here tested specimens. Interesting finding is that with lower value of strength, the finished Ultrafuse $316 \mathrm{LX}$ product offers almost $40 \%$ higher value of ductility in comparison with values from datasheet. In this view, the 3D printed samples overcome even the rolled material. Two groups of specimens which underwent debinding and sintering in BASF and Vibrom Company show very similar performance. On the other hand, the specimens finished at TUL evince considerably worse mechanical behaviour. This is most probably caused by lack of dedicated equipment and nontypical process of debinding. Final structure may contain traces of binder and thus the final performance is limited. This topic needs deeper analysis for finding where the problem is and adjustment of finishing methods.

In the case of SLM-printed specimens, the results follow data published by the manufacturer. The material itself is more brittle than both rolled material and Ultrafuse $316 \mathrm{LX}$. This phenomenon might be influenced by subsequent heat treatment, specifically solution annealing [Waqar 2020] [Kamariah 2020].

\section{CONCLUSION}

Main aim of this article was a direct comparison of FFFmanufactured Ultrafuse $316 \mathrm{LX}$ material with rolled material of the same kind and SLM-processed specimens. Secondly, the possibility of using the FFF technology for production of fully functional metallic parts was evaluated. In the frame of this work, it was decided to fabricate tensile test samples using commercially available BASF Ultrafuse $316 \mathrm{LX}$ material. Apart from this material, standard $316 \mathrm{~L}$ steel was also tested for a possibility to compare final behaviour of FFF-produced samples with the conventional ones. Last set of specimens was produced using Selective Laser Melting technology for which the $316 \mathrm{~L}$ powder is one of today's standard materials. Even this group serves as an interesting model for comparison of the data with another additive technology for manufacturing of metal parts.

One of the main finding of this paper is that it is possible to use very cheap desktop printers for fabrication of metallic models, more specifically the semi-finished products. BASF Ultrafuse 316LX Filament was easy to process after fine tuning of FFF technological parameters provided by the manufacturer. As a result, initial investment for fabrication of metal parts can be affordable for large number of companies. For the following two finishing steps, one has to be equipped with specific devices for debinding and sintering. In this view, the price of final model rises significantly because of need of relatively expensive and demanding machines. On the other hand, this can be also solved by submitting green part to a company which ensures the whole post-processing. This way was also applied in this work as two sets of specimens were submitted to BASF and Vibrom companies.

Tensile tests revealed that the material Ultrafuse $316 \mathrm{LX}$ does not reach values of ultimate tensile stress and yield stress typical for rolled 316L material. On the other hand, it offers more ductility which may be advantage in certain applications. Overall, these kinds of materials offer promising possibilities for further research and development of new types of design. Following work will thus be carried out to test other properties such as shrinkage, shape precision, porosity and deeper material-related analyses.

\section{ACKNOWLEDGMENTS}

This work was supported by the Student Grant Competition of the Technical University of Liberec under the project No. SGS2019-5012.

\section{REFERENCES}

[AZOM 2020] https://www.azom.com, 2020, available from https://www.azom.com/article.aspx?ArticlelD=2382

[Buchanan 2019] BUCHANAN, Craig; GARDNER, Leroy. Metal 3D printing in construction: A review of methods, research, applications, opportunities and challenges. Engineering Structures, 2019, 180: 332-348.

[Chua 2014] CHUA, Chee Kai; LEONG, Kah Fai; LIM, Chu Sing. Rapid prototyping: principles and applications (with companion CD-ROM). World Scientific Publishing Company, 2010.

[Desktopmetal 2020] desktopmetal.com, 2020, available from https://www.desktopmetal.com

[Fernandez 2015] FERNANDEZ-VICENTE, Miguel; CANYADA, Miquel; CONEJERO, Andres. Identifying limitations for design for manufacturing with desktop FFF 3D printers. International Journal of Rapid Manufacturing, 2015, 5.1: 116-128

[Forward AM 2020] forward-am.com, 2020, available from https://forward-am.com/find-material/filaments/ultrafuse316l/

[Gibson 2014] GIBSON, lan, et al. Additive manufacturing technologies. New York: Springer, 2014.

[Gong 2018] GONG Haijun, CRATER Cameron, ORDONEZ Ana, WARD Craig, WALLER Madison, GINN Charles : Material Properties and Shrinkage of 3D Printing Parts using Ultrafuse Stainless Steel 316LX Filament MATEC Web Conf. 24901001 , 2018.

[Kamariah 2020] KAMARIAH, MS IN, et al. Mechanical Behaviours of Selective Laser Melting 316L Stainless Steel. Journal of Additive Manufacturing and Advanced Materials, 2020, 1.1: 01-18.

[Markforged 2020] Markforged.com, 2020, available from https://markforged.com/3d-printers/metal-x

[SLM 2020] SLM $^{\circledR}$ Metal Powder, 2020, available from www. slm- solutions.com/en/products/accessoriesconsumables/slmr- metal- powder/

[Thompson 2019] THOMPSON, Yvonne, et al. Fused filament fabrication, debinding and sintering as a low cost additive manufacturing method of $316 \mathrm{~L}$ stainless steel. Additive Manufacturing, 2019, 30: 100861.

[Waqar 2020] WAQAR, Saad, et al. Effect of post-heat treatment cooling on microstructure and mechanical properties of selective laser melting manufactured austenitic $316 \mathrm{~L}$ stainless steel. Rapid Prototyping Journal, 2020.

[Wohlers 2014] WOHLERS, Terry; GORNET, Tim. History of additive manufacturing. Wohlers report, 2014, 24.2014: 118. 


\section{CONTACTS}

Ing. Jiri Safka, Ph.D.

Technical University of Liberec, Faculty of Mechanical Engineering, Department of Manufacturing Systems and Automation, Studentska 1402/2, Liberec 1, 461 17, Czech Republic, +420485353801,

jiri.safka@tul.cz,www.tul.cz 